\title{
A Study on Blended Learning Assessment Methods for Laboratory Intensive Courses Teaching
}

\author{
Guangzhi Qu and Lunjin Lu
}

\begin{abstract}
Blended learning has become more and more popular for educators and students. It is crucial to have appropriate assessment methods to enhance the learning quality and effectiveness of teaching. Lab intensive course teaching poses more challenges. In this study, traditional assessment methods, i.e., lab exercises, demonstration, written report, and multiple choice questions are combined in an innovative way. End of course evaluation and course grade reveal that the students benefit more by getting higher marks in the blended assessment compared to the written questions alone process during a two-year experiment.
\end{abstract}

Index Terms-Blended learning, assessment methods, laboratory intensive courses teaching.

\section{INTRODUCTION}

In recent years, blended learning has become popularly accepted as a way of learning and teaching in higher education. Traditional face-to-face instructor-led teaching has been augmented through combining various e-learning technologies, pedagogical approaches, and instructional methods to accomplish optimal educational learning outcome [2]. The key to the success of blended learning depends on the strategy adopted in selecting the right combination of media that will bring highest throughput using lowest possible cost and simpler e-learning tools [1].

The widely deployed World Wide Web and popularity of various social networking techniques empowers the development of many e-learning tools for delivering, tracking, and managing education and training. They are WebBoard, WebCt, Blackboard, Sakai, Moodle, myCodeMate, and WileyPLUS, just name a few. Using these systems, a virtual learning environment is created so that students can learn anytime, anywhere after class. The communications between students and instructors, and the students themselves have been strengthened in the virtual learning environment. A wide variety of digital learning content are integrated into the virtual learning environment easily that makes both teaching and learning more efficient and effective. Moreover, some systems provide interactive functions, such as online forum and exercises, which help actively manage the progress of group projects and learn how to apply techniques to solve real-world problems.

Course learning assessment is the process faculty use to grade student performance in the course. It is one of the critical parts to collect information systematically on the

Manuscript received August 20, 2012.; revised October 29, 2012.

The authors are with Computer Science and Engineering Department, Oakland University, Rochester, MI 48309 USA (e-mail: gqu@oakland.edu, 12lu@oakland.edu). success of overall course, program and university curriculum. The goal of course learning assessment has three-fold: 1) the course learning objectives can be linked effectively and consistently along the assignments, exams, course structure, grading, and the actual teaching; 2) instructors can be informed on what does work and what does not in their classrooms or the virtual learning environment; 3) students have direct feedback on their own progress in the learning.

Due to the nature of the subject, some courses have a significant laboratory component in order to accomplish the educational goals. For example, system administration course for undergraduate students majored in Information Technology at Oakland University requires the students to acquire skills in different aspects of the system administration through individual hand-on assignments and group projects. We adopted blended learning mode for this course that we have face-to-face classroom teaching, lab sessions and the course content is managed through Moodle. Homework assignments and exams are popular methods for course learning assessment. For laboratory intensive course, the assessment poses more challenges to the instructors to assure the quality of learning.

In this study, we proposed to utilize blended assessment methods to combine the traditional assessment method in an innovative way that written questions were authored and instructed in the lab sessions, based on the results of submitted written assignment, multiple choice questions were designed to reinforce the learning.

The rest of the paper is organized as follows. In Section II, related work will be presented. Section III describes the different assessment methods and new challenges. Section IV gives the experiments for blended assessment in the laboratory intensive course. Section V shows the results. We conclude our work in Section VI.

\section{RELATED WORK}

Computer Information Technology (CIT) is a discipline that explores how to design and deploy computer-based techniques to solve real world problems. Therefore, it is crucial to improve students' comprehension and retention of concepts and principles of information technology in order to empower them with necessary skills to solve problems outside of the classroom. One way to accomplish the goal is through laboratory activities. Particularly in courses like system administration (CIT 348), intensive laboratory activities will play a distinctive and central role in the curriculum. These laboratory activities are designed to knit course concepts into 'real-world' problems that students will learn the knowledge by exploring methods through first-hand experience. 
The opportunities from laboratory intensive courses obviously differ from those in a standard classroom environment in that the students will learn both theoretical concepts and practical experience. Educators and instructors are facing the particular challenges on how to assess students learning of such courses.

TABLE I: MOODLE ASSIGNMENT TYPES

\begin{tabular}{|c|c|}
\hline Question Type & Definition \\
\hline Multiple Choice & $\begin{array}{l}\text { Allows the selection of a single or multiple } \\
\text { responses from a pre-defined list. }\end{array}$ \\
\hline Short Answer & $\begin{array}{l}\text { Allows a response of one or a few words that } \\
\text { is graded by comparing against various model } \\
\text { answers, which may contain wildcards. }\end{array}$ \\
\hline Numerical & $\begin{array}{l}\text { Allows a numerical response, possibly with } \\
\text { units, that is graded by comparing against } \\
\text { various model answers, possibly with } \\
\text { tolerances. }\end{array}$ \\
\hline Calculated & $\begin{array}{l}\text { Calculated questions are like numerical } \\
\text { questions but with the numbers used selected } \\
\text { randomly from a set when the quiz is taken. }\end{array}$ \\
\hline Essay & $\begin{array}{l}\text { Allows a response of a few sentences or } \\
\text { paragraphs. This must then be graded } \\
\text { manually. }\end{array}$ \\
\hline Matching & $\begin{array}{l}\text { The answer to each of a number of } \\
\text { sub-question must be selected from a list of } \\
\text { possibilities. }\end{array}$ \\
\hline $\begin{array}{l}\text { Random short } \\
\text { answer } \\
\text { matching }\end{array}$ & $\begin{array}{l}\text { Like a Matching question, but created } \\
\text { randomly from the short answer questions in a } \\
\text { particular category. }\end{array}$ \\
\hline $\begin{array}{l}\text { Embedded } \\
\text { answers }\end{array}$ & $\begin{array}{l}\text { Questions of this type are very flexible, but } \\
\text { can only be created by entering text containing } \\
\text { special codes that create embedded } \\
\text { multiple-choice, short answers and numerical } \\
\text { questions. }\end{array}$ \\
\hline $\begin{array}{l}\text { Calculated } \\
\text { multi-choice }\end{array}$ & $\begin{array}{l}\text { Calculated multichoice questions are like } \\
\text { multichoice questions which choice elements } \\
\text { can include formula results from numeric } \\
\text { values that are selected randomly from a set } \\
\text { when the quiz is taken. }\end{array}$ \\
\hline $\begin{array}{l}\text { Calculated } \\
\text { simple }\end{array}$ & $\begin{array}{l}\text { A simpler version of calculated questions } \\
\text { which are like numerical questions but with } \\
\text { the numbers used selected randomly from a set } \\
\text { when the quiz is taken. }\end{array}$ \\
\hline $\begin{array}{l}\text { Drag and drop } \\
\text { into text }\end{array}$ & $\begin{array}{l}\text { Missing words in some text are filled in using } \\
\text { drag-and-drop. }\end{array}$ \\
\hline $\begin{array}{l}\text { Drag and drop } \\
\text { markers }\end{array}$ & $\begin{array}{l}\text { Markers are dragged and dropped onto a } \\
\text { background image. }\end{array}$ \\
\hline $\begin{array}{l}\text { Drag and drop } \\
\text { onto image }\end{array}$ & $\begin{array}{l}\text { Images or text labels are dragged and dropped } \\
\text { into drop zones on a background image. }\end{array}$ \\
\hline $\begin{array}{l}\text { Select missing } \\
\text { words }\end{array}$ & $\begin{array}{l}\text { Missing words in some text are filled in using } \\
\text { dropdown menus. }\end{array}$ \\
\hline True/False & $\begin{array}{l}\text { A simple form of multiple-choice question } \\
\text { with just the two choices 'True' and 'False'. }\end{array}$ \\
\hline
\end{tabular}

The goal of assessment is to improve the teaching and learning process. Homework assignments and exams are popular methods for course learning assessment. Traditionally, homework assignment is taken by individual student or a group of students and exams are administrated on paper to measure the student's knowledge and skills [3]. For the laboratory intensive courses, it is difficult to design purely written assignments and exams to assess the quality of the learning. Laboratory exercises and projects are the common means used in the teaching. However, there exist concerns on whether the students understand thoroughly the theoretical foundation besides the skillful hand-on experience in problem solving.

As the proliferation of e-learning technologies, online assessment emerges as a popular form of method to give feedback for instructors and students on what has been taught well and what has learned well. It is also more economical use of the instructors' time. In the e-learning environment, assessment questions can shift the emphasis from procedural skills to the higher order thinking skills such as interpretation.

MOODLE is an acronym for Modular Object Oriented Dynamic Learning Environment and has been widely used by educational institutions. It is designed to provide different tools for instructors: 1) course websites management, the instructors can create and navigate course websites according to the semester the course is offered, import a course website from other semester, outcomes, course site backup and restore, reset; 2) Assignment administration, the instructor can define the assignment submission parameters, whether a late submission is allowed and notify the grader, grade configuration, assigning roles including teacher, non-editing teaching/TA or editing TA w/o grading access, activities log, backup and restore, submissions management; 3) Activities management, the instructor can create forum for the feedback and communications between instructor and students and among the students, administrate quizzes and manipulate resources including lecture slides. All the users (teacher or students) are assigned user accounts and passwords for security consideration. Moodle can provide functions to build a question bank. Table I shows the different types of questions.

Among the various formats of online assessment methods, Multiple-Choice Questions (MCQ) has been widely used in computer based assessment due to easy use and convenience in collecting test scores and feedback through the application programming interface (API) provided by the e-learning environment [4], [5].

However, some disadvantages exist for the MCQ compared with written assessment. Principle among these is the argument that it is difficult for the instructors to know whether students can demonstrate successfully knowledge levels appropriate to their test scores. The students will use the strategies of guessing or a process of elimination during a MCQ test when they are not certain about some questions. Moreover, if the students know the end-of-assessment will be composed of MCQ then learning process may be fused with more superficial facts memorizing instead of in-depth understanding of the underlying concepts.

Our philosophy on using the MCQ lies in the fact, it is effective to test the key concepts and the knowledge required memorizing. Moreover, the MCQ bank created will be a good supplement to the regular laboratory exercises, written assignments and reports, demonstration that it can help reinforce the learning

\section{COURSE DESCRIPTION}

In this study, we focus on the CIT 348 System Administration course taught at Oakland University, which is one of the core courses for students on the system administration track and is offered twice a year - summer session and regular fall semester. The students registered in 
this course include junior or the first semester senior students. Every semester we will have around 30 students enrolled. According to the university catalog, the course is described as follows:This course teaches the skills necessary to analyze, deploy, manage and troubleshootenterprise computing infrastructures. Topics include file system management, systemconfiguration, period tasks automation, network monitoring and management, servicesdeployment, and system performance analysis techniques. This course has aSIGNIFICANT LAB component.

Upon finishing this course, the student will be able to accomplish the objectives shown in Table II.

\begin{tabular}{ll} 
TABLE II: CIT 349 COURSE OBJECTIVES \\
\hline \hline No. & Course Objectives \\
\hline 1 & Understand and explore the Linux file system. \\
& $\begin{array}{l}\text { Understand major features of the BASH Shell } \\
\text { including redirection, piping,variables, aliases, } \\
\text { and environment files. }\end{array}$ \\
& $\begin{array}{l}\text { Understand processes as well as how to view } \\
\text { their attributes, change their priority,kill them } \\
\text { and how to schedule processes. }\end{array}$ \\
& $\begin{array}{l}\text { Understand log file administration and user } \\
\text { administration. }\end{array}$ \\
& $\begin{array}{l}\text { Understand network configuration including } \\
\text { networks, network utilities, } \\
\text { TCP/IPconfiguration on NIC, name } \\
\text { resolution, common networking services and }\end{array}$ \\
Linuxserver administration from remote end. \\
5
\end{tabular}

In order to carry out the course, six laboratory assignments are designed on the following topics: 1) exploring Linux file system; 2) managing file system; 3) working with BASH Shell; 4) managing processes; 5) configuring network; 6) configuring network services (web server, dns server, dhcp, etc.); 7) trouble shooting, performance monitoring and introduction to security.

\section{Assessment Methodology}

Use In this study, existing methods of assessment are combined in an innovative way. Students are asked to work out the laboratory exercises according to the instruction in the lab session, put answers to the questions in a written report and submit online, demonstrate to the teaching assistants on certain parts of the activities. After all the written reports being received and graded, the teaching assistant and instructor summarize the weak learning points and common mistakes, 15 to $20 \mathrm{MCQ}$ questions were authored and delivered through Moodle. This assessment procedure is introduced at the beginning of each semester to the students and also described detailed in the course syllabus. So the students can be actively involved in the learning process. Even they couldn't answer certain written question correctly in the lab session; they will study the problems in order to overcome the following assessments.

\section{A. Case Study 1-BASH Shell}

BASH shell is very important for the system administrator to carry out administration tasks. We have created laboratory exercises for the students to work. These questions cover the following aspects: 1) Redirect the input and output of a command; 2) Identify and manipulate common shell environment variables; 3) Create and export new shell variables; 4) Edit environment files to create variables upon shell startup; 4) Describe the purpose and nature of shell scripts; 5) Create and execute basic shell scripts; and 6) Effectively use common decision constructs in shell scripts. Sample questions are shown in Fig. 1.

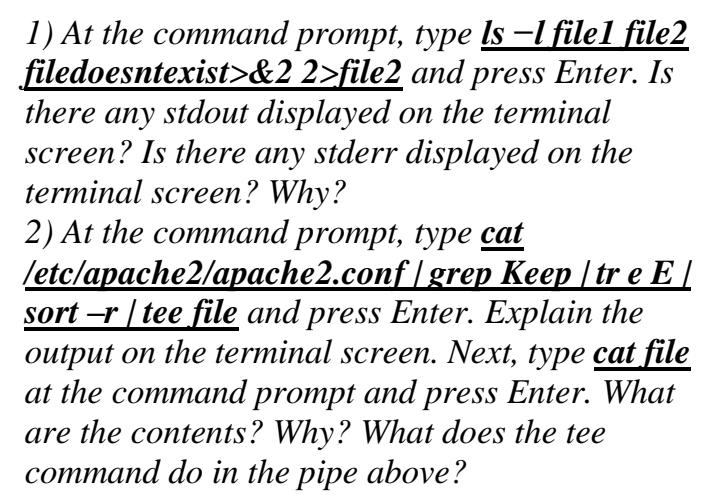

Fig. 1. Sample questions for BASH shell

Which command is most useful when you want
not only to send some data down a pipe, but also
to save a copy?
(a) pipe
(b)awk
(c)sed
(d)tee (correct answer)

Fig. 2. Sample quiz question for shell

The BASH shell laboratory exercises are designed for each individual student to follow the instructions to practice on the Virtual Machine created from the cluster computing environment at Oakland University. The students are asked to answer the questions while doing laboratory exercises. After the students finish the assignment and submit the written answers, the instructor and teachingassistant will count the questions on which the students didn't perform well or still have doubts on certain concepts. Then multi-choice questions are design and delivered through Moodle. One example shown in Fig. 2 is that the students couldn't under the function of a common Linux routine of 'tee'.

\section{B. Case Study 2 - Building a Network}

For example, to build a network the students need to understand the IP addressing, routing protocols and also 
different configuration tools (ifconfig, ip, route, etc.).One of the assignments for a group of three students is to set up a network of three routers as shown in Fig. 3. The assessment consists of three parts: 1) demonstration to teaching assistant in the lab; 2) written report to answer questions designed in Fig. $4 ; 3)$ a quiz after the grading to reinforce the learning shown in Fig. 5.

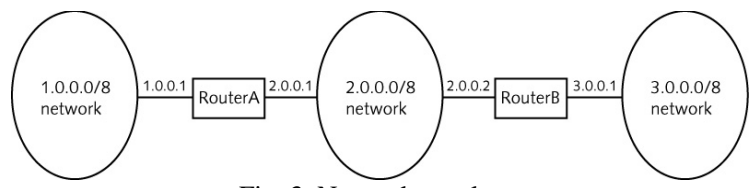

Fig. 3. Network topology

In the network you have built shown in Figure 3, in order to have a node 'client' from 1.0.0.0/8 network to have conversation with a node 'server' from 3.0.0.0/8 network, what routing entries you should add to the routing tables of the RouterA and RouterB?

Fig. 4. Assessment written question

In the network you have built in the lab 5, what the default gateway ip address for

Router A and Router B?

(a) 3.0.0.1 and 1.0.0.1

(b)2.0.0.2 and 2.0.0.1 (correct answer)

(c) 2.0.0.2 and 1.0.0.1

(d)3.0.0.1 and 2.0.0.1

Fig. 5. Sample quiz question for network

We found a lot of students can successfully add relevant routes into the Routers A and B's routing tables from the laboratory exercises reflected from the demonstration the results to teaching assistant on the written report. However, we would like to reinforce the learning on the concept of default routing, so we designed the quiz question in Fig.5.

\section{RESULTS AND DISCUSSION}

To demonstrate the effectiveness of blended assessment approaches, in this study, we deployed both the traditional teaching methodology and the blended assessment methodology and they were experimented at the Oakland University for CIT 348 (System Administration) course over four semesters in a two year study. A total of 82 students were assessed in this method.The traditional assessment method was used in two semesters and the blended assessment method in the following two semesters. As it is the first class on system administration, the instructor chose to provide more teacher guidance besides the teaching assistant. The outcomes are shown in Table I. The instructor collected the results from both teachers' and students' perspective. On a 5-grade scale, students evaluated the instructor from 17 aspects shown in Table III.

\section{A. Qualitative Testimonials}

There are many comments on the method of blended assessment from a few students. These include:

"Great Professor!! Helped out with everything and taught the class well so that it was easier for the students to understand."

"Overall, I've gained a lot of knowledge about systems administration. The course was challenging at times but academically fulfilling at the same time."

"The course was well-balanced with lecture and lab as the labs supported everything which was taught in the classroom.

The course provided skills which can be applied in an IT-related job."

"Instructor gave us quizes nearly every other class, which I think is a great learning tool".

TABLE III: CIT 349 COURSE EVALUATION SURVEY QUESTIONS

\begin{tabular}{|c|c|}
\hline No. & Questions \\
\hline 1 & $\begin{array}{l}\text { The instructor did a good job of making the } \\
\text { objectives of the course clear to me. }\end{array}$ \\
\hline 2 & $\begin{array}{l}\text { The instructor did a good job in developing and } \\
\text { presenting the material in a clear and organized } \\
\text { manner. }\end{array}$ \\
\hline 3 & $\begin{array}{l}\text { The instructor stimulated and deepened my } \\
\text { interest in the subject. }\end{array}$ \\
\hline 4 & The instructor motivated me to do my best work. \\
\hline 5 & $\begin{array}{l}\text { Explaining and clarifying difficult material and } \\
\text { problem solutions. }\end{array}$ \\
\hline 6 & $\begin{array}{l}\text { Willingness to provide individual assistance to } \\
\text { students outside of classroom hours. }\end{array}$ \\
\hline 7 & Ability to handle questions from the class. \\
\hline 8 & Utilization of class time. \\
\hline 9 & $\begin{array}{l}\text { Utilization of instructional aids such as } \\
\text { blackboard, slides or viewgraph. }\end{array}$ \\
\hline 10 & Uniformity and impartiality in grading. \\
\hline 11 & $\begin{array}{l}\text { Promptness in returning homework, laboratory } \\
\text { reports and examinations. }\end{array}$ \\
\hline 12 & Overall rating as a teacher. \\
\hline 13 & Value of the textbook contribution to the course. \\
\hline 14 & Value of the recitation component of the course. \\
\hline 15 & Value of the laboratory component of the course. \\
\hline 16 & $\begin{array}{l}\text { Please rate the adequacy of the computing and/or } \\
\text { laboratory facilities. }\end{array}$ \\
\hline 17 & $\begin{array}{l}\text { Please provide an overall rating of this course as a } \\
\text { learning experience. }\end{array}$ \\
\hline
\end{tabular}

\section{B. Discussion}

We have to admit that the blended assessment method will require extra efforts from the instructors in providing the enhanced multi-choice questions dynamically. The students' background may vary from semester to semester, the multi-choice questions bank has to be adaptive to suit the different learning experience, which request more efforts from the instructor.

\section{CONCLUSION}

In this paper, we described blended assessment method for laboratory intensive course teaching in computer information technology. From our experience, we find that, for the laboratory intensive courses, the blended assessment should be used to achieve the optimal learning result.

\section{REFERENCES}

[1] J. Bersin. What Works in Blended Learning, Learning Circuits [Online]. http://www.learningcircuits.org/2003/jul2003/bersin.htm.

[2] M. Driscoll. Blended Learning: Let's get beyond the hype. [Online]. Available: 
http://www.elearningmag.com/ltimagazine/article/articleDetail.jsp?id $=11755$.

[3] R. Linn and D. Miller, "Measurement and Assessment," presented at the 9th edition Pearson Prentice Hall, New Jersey, USA, 2005.

[4] G. G. Roy and J. Armarego, "The Development of On-line Tests Based on Multiple Choice Questions," Idea Group Publishing, 2003.

[5] D. Taniar and J. W. Rahayu, "On-Line Multiple Choice Testing," Web-Powered Data Base.Idea Group Publishing, 2003.

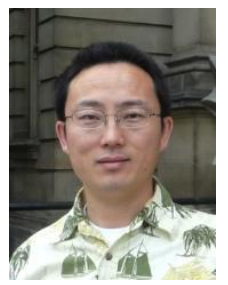

Guangzhi Qu received his Ph.D. in computer engineering from The University of Arizona in2005 He received his Masters and Bachelor degrees both in Computer Science and Engineering from Beijing University of Aeronautics and Astronautics in 1999 and 1996 respectively.He joined the Computer Science and Engineering department at Oakland University in 2007. His research interests include data mining and machine learning, healthcare computing and biomedical informatics, network security, and discrete event based simulation.Dr. Qu is a senior member of IEEE and a member of ACM.

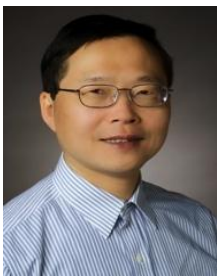

Lunjin Lu received his Ph.D. in computer science from The University of Birmingham.He is an associate professor with Oakland University. His work has focused mainly on semantic based program analysis; logicprogramming; and software development tools. Current research includesstatic program analysis, refinement of software models, multi-coreprogramming and computer aided instruction. 